Originally published as:

Köndgen, S., Schenk, S., Pauli, G., Boesch, C., Leendertz, F.H.

Noninvasive monitoring of respiratory viruses in wild chimpanzees (2010) EcoHealth, 7 (3), pp. 332-341.

DOI: 10.1007/s10393-010-0340-z

This is an author manuscript.

The definitive version is available at: http://www.springerlink.com/ 


\title{
Noninvasive Monitoring of Respiratory Viruses in Wild Chimpanzees
}

\author{
Sophie Köndgen, ${ }^{1}$ Svenja Schenk, ${ }^{1,2}$ Georg Pauli, ${ }^{1}$ Christophe Boesch, ${ }^{2}$ and Fabian H. Leendertz ${ }^{1}$ \\ ${ }^{1}$ Robert Koch-Institut, Nordufer 20, 13353 Berlin, Germany \\ 2 Department of Primatology, Max Planck Institute for Evolutionary Anthropology, Deutscher Platz 6, \\ 04103 Leipzig, Germany
}

To diagnose respiratory disease among wild great apes, there is a need for noninvasive diagnostic methods. Therefore, we analyzed fecal samples from habituated chimpanzees from Taï National Park, Côte d'Ivoire. Samples had been collected during four distinct outbreaks: two with known aetiology (March 2004 and February 2006) and two with unknown aetiology (October 2004 and August 2005). Fecal samples were screened by polymerase chain reaction (PCR) for the presence of human metapneumovirus (HMPV) and human respiratory syncytial virus (HRSV), two paramyxoviruses previously found in lung tissue of chimpanzees that died due to respiratory disease. In the March 2004 outbreak, $72 \%$ of the tested individuals were positive for HMPV, and during the 2006 epidemic, 25\% tested HRSV-positive. In the outbreaks where no causative pathogen was previously known, fecal samples tested positive for either HRSV or HMPV, showing that reinfection occurred. Virus sequences were generated and compared with sequences previously found in tissue; nearly identical virus sequences in both tissue and fecal samples were found. These results demonstrate that fecal samples collected during outbreak times can be used for the diagnostic and phylogenetic analysis of HMPV and HRSV. Using such diagnostic tools, systematic noninvasive disease investigation of respiratory outbreaks in wild great apes becomes possible. The methods presented here may also be applied for the investigation of further acute diseases in great apes and other species.

\section{Introduction}

Respiratory disease is the most important cause of morbidity and mortality among wild great apes habituated to human presence, for research or tourism, and thus presents major conservation concerns (Goodall, 1986; Homsy, 1999; Boesch and Boesch-Achermann, 2000; Woodford et al., 2002; Nishida et al., 2003; Hanamura et al., 2008). Therefore, the evaluation of the occurrence and prevalence of respiratory pathogens in wild primate populations is essential for designing successful management and conservation strategies. Frequent contact between humans and wild primates increase the likelihood of pathogen exchange between human and nonhuman primates (Homsy, 1999; Leendertz et al., 2006; Gillespie et al., 2008). Anthropozoonotic transmission of the paramyxoviruses respiratory syncytial virus (HRSV) and human metapneumovirus (HMPV) from humans to wild chimpanzees, resulting in several respiratory disease outbreaks, has been shown in the chimpanzees of Taï National Park, Côte d'Ivoire and in Mahale, Tanzania (Kaur et al., 2008; Köndgen et al., 2008). Both viruses are known to cause respiratory symptoms in captive chimpanzees, in some cases leading to mortalities (Clarke et al., 1994; Skiadopoulos et al., 2004; Szentiks et al., 2009). HRSV and HMPV are common respiratory pathogens in humans, and the leading causes of lower respiratory disease in children (Weber et al., 1998; Boivin et al., 2003).

To diagnose infections with paramyxoviruses in wild chimpanzees, systematic testing of symptomatic and asymptomatic individuals is important. In humans, diagnosis of respiratory disease is performed based on throat or nasal swabs. These materials cannot be obtained from large numbers of wild great apes without anesthesia, which harbors various risks, especially when performed on weakened and/or symptomatic individuals. Therefore, methods are needed which allow reliable pathogen detection in materials which can be collected noninvasively and without disturbing the chimpanzee's behavior, such as feces, urine, or saliva from food remains (e.g., food wadges). Until now, noninvasive methods have been used mainly for the detection of gastrointestinal pathogens or systemic chronic viruses, such as simian immunodeficiency virus, simian foamy virus, and hepatitis B virus, which can be found in feces (Santiago et al., 2002; Makuwa et al., 2005; Keele et al., 2006; Liu et al., 2008). In respect to the detection of pathogens causing acute diseases, noninvasive diagnostics of fecal samples are well established for pathogens affecting the gastrointestinal tract (e.g., bacteria, viruses, parasites, fungi). Recently, it has been shown that the detection of respiratory viruses is also possible from fecal 
samples, namely, HRSV RNA has been found in fecal samples from human infants (von Linstow et al., 2006) and HMPV RNA was detected in fecal samples from two habituated chimpanzees at the research site in Mahale, Tanzania (Kaur et al., 2008). Both studies used polymerase chain reaction (PCR)-based methods for the screening of fecal samples, but in the human study, the sensitivity of the methodology was low, and in the chimpanzee study, only a few samples were available.

The aim of our study was to evaluate the applicability of PCR-based analysis of fecal samples as a screening tool to examine infections with HRSV and HMPV in chimpanzees. Therefore, fecal samples collected during a HMPV epidemic (2004), a HRSV epidemic (2006), and two respiratory outbreaks with unknown aetiology in 2004 and 2005, in one chimpanzee community in Taï National Park, Côte d'Ivoire were tested for the presence of HRSV and HMPV.

\section{Materials and Methods}

\section{Observations and Sample Collection}

Four communities of chimpanzees of the Taï National Park, Côte d'Ivoire, have been habituated and are followed on a daily basis (Boesch and Boesch-Achermann, 2000; Boesch et al., 2006, 2008). The South group that is subject of the present analysis was habituated in 1995 (Herbinger et al., 2001).

Since 2001, a veterinary unit has been permanently assigned to the Taï chimpanzee project to broadly monitor disease and health in the chimpanzee population. When individuals show signs of weakness or symptoms of illness, detailed clinical observations are recorded: coughing, sneezing, presence and quality of nasal discharge (e.g., clear vs. yellow or white), and the quality and quantity of respiration. In addition, routine observations of activities, such as eating, drinking, social interactions with other individuals or offspring for adult females, are intensified (Leendertz et al., 2006). Also, over the entire time of the disease outbreak, the presence and absence of all individual chimpanzees in the affected group is documented.

Fecal samples are collected continuously from symptomatic and asymptomatic chimpanzees immediately after defecation and are assigned to the respective individual; thus samples can be linked to age, sex, and the presence of symptoms. Samples are then transported on ice to the field camp, preserved in liquid nitrogen, and thereafter sent to the Robert Koch-Institute for molecular analyses.

Fecal samples analyzed in this study originate from four respiratory outbreaks: For two of these outbreaks (March 2004 and February 2006), the causative pathogens have been described through analyses of necropsy samples (Köndgen et al., 2008); for the other two (October 2004 and August 2005), the causative pathogens were not known. The duration of each outbreak was defined by the first and last observed clinical symptoms in the group. Sample size varied between 29-65, depending on the duration of the outbreaks, with 1-12 samples collected per day and between 1-7 samples collected from individual chimpanzees over the course of an outbreak. As a control, two sets of samples were tested: First, samples were selected from a 4-week period in June/July 2005, when the whole group appeared healthy and showed no respiratory symptoms. Samples were chosen from the same individuals that had been tested during outbreak times, resulting in a total of 21 individuals that were tested for the presence of HMPV and HRSV (one sample each). Second, to determine if HMPV and HRSV were persistent in affected individuals, additional samples which had been collected in the time between consecutive outbreaks were tested (33 samples from 10 individuals) (Table 1).

\section{Molecular Analysis}

\section{Extraction of Nucleic Acids}

RNA was extracted from approximately $60 \mathrm{mg}$ feces using the GeneMATRIX Stool DNA Purification Kit (Roboklon, Berlin, Germany) according to manufacturers instructions, aside from a minor modification in the first step, where 5 II of carrier-RNA were added to the bead tubes containing the dispersion and lysis buffer. It should be noted that the kit was specified for recovery of DNA, but viral RNA was co-purified. cDNA was synthesized using the Superscript Kit (Invitrogen, Karlsruhe, Germany) and random hexamer primers (TIB Molbiol, Berlin, Germany). 


\section{Screening}

Samples were screened for HRSV and HMPV using a generic Taqman PCR (Stratagene, Waldbronn, Germany). For HRSV, PCR was performed as described previously (Reiche and Schweiger, 2009) but with a modification of the probe (FAM-ACAGGAGATARTATTDAYACTC-NFQ MGB). Information on the HMPV assay will be described elsewhere [Reiche, in preparation; sequence information of primers and probes on request].

Samples were screened in duplicate and PCR products of the HRSV- and HMPV-positive samples were additionally analyzed by electrophoresis in a $2 \%$ agarose gel. To control for false-negative results due to PCR inhibitors, negative-tested CDNA samples were diluted 1:10 in $\mathrm{H} 20$ and retested. Positive and negative controls were included in each run.

\section{Phylogenetic Analysis}

Randomly, positive samples with a viral load $>10$ copies/ll cDNA (determined by Taqman PCR) were selected for further characterization by PCR assays targeting phylogenetically relevant DNA fragments (4/21 for the 2004, 4/22 for the 2005, and 3/6 for the 2006 outbreak). Concerning the HRSV outbreaks, we included samples from individuals that had been tested positive in both 2005 and 2006 $(n=3)$.

For HRSV, first and hemi-nested PCRs targeting the hypervariable region of the $G$ protein were performed. The subgroup B-specific primers used for the first PCR were primer GPB and F1. Those used for the hemi-nested PCR were primers nRSBG and F1, as described previously (Sato et al., 2005). To amplify the $P$ Gen of HMPV, which is commonly used for phylogenetic analyses, the primers MPVP01.6 and MPVM02.4 were used, as described by Mackay et al. (2004). Amplification was conducted for $5 \mathrm{~min}$ at $95^{\circ} \mathrm{C}$, followed by 35 cycles of $95^{\circ} \mathrm{C}$ for $30 \mathrm{~s}, 54^{\circ} \mathrm{C}$ for $30 \mathrm{~s}$, and $72^{\circ} \mathrm{C}$ for $1 \mathrm{~min}$, with a final $10 \mathrm{~min}$ of extension at $72^{\circ} \mathrm{C}$. PCR products were analyzed by electrophoresis in a $1.5 \%$ agarose gel, and positive samples were purified using Exo-SAP (USB Europe GmbH, Staufen, Germany). When multiple bands were present, the expected band (458 bp for HRSV and 937 bp forHMPV) was cut out of the gel, purified using the Gel Extraction Spin Kit (Genomed, Loehne, Germany) and then cloned with the Topo TA Cloning Kit (Invitrogen). Colonies were analyzed by colony PCR, and positive samples were purified with ExoSAP. Sequencing was performed using the ABI Big Dye Termination Kit (Applied Biosystems, Weiterstadt, Germany).

Viral sequences generated from feces were compared to sequences previously generated fromtissue samples (Köndgen et al., 2008) using BioEdit.version 7.0.9 (Hall, 1999). Analysis of Observational and Molecular Data The incidence of respiratory disease was calculated for every outbreak based on both molecular data (percentage of positive-tested individuals) and observational data (percentage of individuals observed with symptoms), and is shown in Figure 1. Differences in the number of positivetested individuals between outbreaks caused by the same virus were calculated using the McNemar test, and based on repeated observations of the same respective individuals. We used exact test since the sample sizes were small (Siegel and Castellan, 1988; Mundry and Fischer, 1998). A P-value $<0.05$ was considered significant.

To compare molecular and observational data, the percentages of observed symptomatic individuals and PCRpositive fecal samples were plotted against the time course of the respective outbreaks, including the mean viral load of the samples (Fig. 2). Since sample size ranged from 1-12

samples per day, data from every 2 days was pooled to avoid sample sizes smaller than two. Observational data was pooled in the same way to fit the molecular data. Between 2 and 35 chimpanzees were observed per day during the outbreaks. 


\section{Results}

For the respiratory outbreak in March 2004, with known involvement of HMPV, fecal samples were tested for HMPV by Real-Time PCR. Sixty-five fecal samples collected from 29 chimpanzees were analyzed and $72 \%$ of the individuals tested positive. For the following two outbreaks in October 2004 and August 2005, from which no necropsy samples are available, 29 and 60 fecal samples from 15 and 24 individuals, respectively, were screened for HMPV and HRSV. From the outbreak in October 2004, only one individual tested weakly positive for HMPV, and, in the August 2005 outbreak, 92\% (22/24) of the individuals were positive for HRSV. From the outbreak in 2006 with known involvement of HRSV, 42 fecal samples from 24 individuals were analyzed and 25\% (6/24) of individuals tested positive for HRSV. All samples collected during non-outbreak times were negative for HMPV and HRSV. The results from the fecal sample screening are summarized in Table 1.

From Real-Time PCR assays, the amount of viral cDNA ranged from 99101 to 1.19105 copies per gram feces for the HMPV assay and from 1.19102 to 6.79105 copies per gram feces for the HRSV assay. On the individual level, copy numbers were usually lower in the beginning and end of the outbreak.

To determine which strains of each virus infected the chimpanzees, we generated sequence information. For HMPV, a 867 bp fragment of the P-Gen, and for HRSV, a 309 bp fragment of the G gene were compared to sequences we had obtained from lung tissue (Gen Bank accession numbers: EU240452 to EU240455) of chimpanzees that had died during these outbreaks. The virus sequences obtained from fecal samples shared $>99.5 \%$ nucleotide identity with those obtained from tissue samples. Sequences from the known HRSV outbreak in 2006 and the outbreak in 2005 of unknown aetiology were identical. Unfortunately, it was not feasible to generate sequences for phylogenetic analyses from the weakly positive samples from the one positive individual from the HMPV outbreak in October 2004, where the analyzed samples contained less than 10 copies/ll cDNA (determined by Taqman PCR). Here, only sequences from the PCR products from the Real-Time PCR were generated, which confirmed the presence of HMPV, pointing towards an involvement of this virus in this outbreak. However, we were not able to compare feces-derived sequences from the known HMPV in the March 2004 outbreak and the consecutive outbreak in the same year.

The virus prevalence for the respective outbreaks is shown in Figure 1, together with the percentages of individuals observed with symptoms. In March 2004, 21 of 29 (72\%) individuals tested positive for HMPV, whereas only one individual tested positive 7 months later in October 2004 . For HRSV, $92 \%$ of individuals tested positive during the outbreak in 2005, and $25 \%$ of individuals tested positive during the second outbreak in 2006. Virus prevalence was always higher in the first HMPV (March 2004) and, respectively, HRSV (August 2005) outbreak than in the consecutives ones. In contrast, only slight differences were observed for the number of symptomatic individuals. For both the HMPV and the HRSV epidemics, there is a significant

difference in the number of infected individuals between the first and consecutive outbreak (exact McNemar test, both $\mathrm{P}<0.001$ ). For both, HMPV and HRSV, the first epidemic lasted longer then the consecutive epidemics (HMPV: 31 days [March 2004] vs. 9 days [October 2004]; HRSV: 22 days [August 2005] vs. 15 days [February 2006]).

Except for the HMPV outbreak in October 2004, all outbreaks were documented in detail, making it possible to compare molecular and observational data over the course of the outbreaks. Therefore, percentages of symptomatic individuals, PCR-positive samples, and respective mean viral load were plotted against the duration of the outbreaks (Fig. 2). Both the molecular and the observational data sets reflect the course of the disease, with fewer symptomatic cases and positive-tested samples, and lower viral load early on, with a progression toward a higher viral load and more symptomatic individuals and positive-tested samples, leading to a peak where almost all individuals were highly infected, prior to a decline in disease symptoms and viral load. 


\section{Discussion}

In recent studies, we were able to show that chimpanzees, which died with symptoms of a respiratory disease, were infected with HMPV or HRSV (Köndgen et al., 2008). However, from these investigations, it was not possible to obtain detailed information on the incidence of infections with these respiratory viruses, due to the fact that diagnostics were based on tissue samples collected from deceased individuals. Systematic data on pathogen prevalence could not be obtained from survivors of these outbreaks or from symptomatic individuals from other, nonlethal outbreaks.

To address this issue, we established methods for the detection of both HRSV and HMPV RNA from fecal samples. Using this noninvasive approach, we were able to calculate the minimum prevalence of HMPV and HRSV among the South group of Taï chimpanzees during respiratory disease outbreaks and to identify the viral causative agents of two respiratory outbreaks with unknown aetiology. In 2005, $92 \%$ of individuals tested positive for HRSV. In October 2004, HMPV was found in fecal samples from one individual which, in connection with the symptoms observed, points towards a possible role of HMPV in this outbreak.

We then compared observational and molecular data over the duration of the outbreaks in March 2004, August 2005, and February 2006. As shown in Figure 2, the PCR results correlate strongly with the observational data, and reveal that there is a relatively broad time frame where the viruses can be detected with noninvasive methods. Viral RNA could be found in feces from 3-4 days after the first symptoms were seen, and was detectable until day 15 (HRSV outbreak 2005), day 11 (HRSV outbreak 2006), and day 26 (HMPV outbreak March 2004), respectively. Due to the heterogeneity of fecal samples, the quantification of their viral load should be considered an approximation. However, looking at the mean viral load over time, the viral load is in line with the course of the outbreaks, therefore we see a lower viral load in the beginning and end, and a high viral load during the peak of the outbreaks (Fig. 2). For phylogentic analysis, we suggest using samples with high viral load (determined by Taqman PCR), due to the lower sensitivity of conventional PCR assays. Therefore, continuous group monitoring and sample collection is important to identify samples from the peak times of an outbreak.

Both HMPV and HRSV are known to replicate only in the respiratory epithelium, and tropism of the gastric or gut mucosa has not been described so far. Hence, an explanation for the finding of paramyxovirus RNA in feces might be that the chimpanzees have swallowed respiratory secretions. It has been shown that paramyxovirus-like particles can be found in stool samples by transmission electron microscopy (Kaur et al., 2008), which could explain why viral RNA is still detectable and not degraded after being transported through the entire gastrointestinal tract. However, it cannot be excluded that these virus replicate in the chimpanzee's gastrointestinal tract. Whether excretion via feces presents a possible route of transmission remains to be investigated, because infectious avian metapneumovirus is known to be shed in the feces of nonvaccinated hens (Hess et al., 2004). However, epidemiologically, this will be a minor factor since chimpanzees of a given group live in close social contact and transmission via smear infection or aerosols is more likely.

As we have shown before, the HRSV strain obtained from deceased chimpanzees in 2006 was closely related to known human strains, suggesting that humans had introduced the virus to the chimpanzee population (Köndgen et al., 2008). Phylogenetic analysis of the virus sequences from fecal samples collected during the outbreak in August 2005 revealed identical sequences to those obtained from tissue/fecal samples from the outbreaks of February 2006.

There are two major groups of HRSV strains, A and B, which are distinguished mainly by variations within the $G$ protein and can be subdivided into different genotypes. Circulation patterns are complex, with several genotypes co-circulating as well as a variety of distinct sequences within each genotype (Cane, 2001). Certain genotypes become dominant and then decline before being replaced by a different dominant genotype. Typically the predominant strain is replaced each year (Peret et al., 2000), but it has also been demonstrated that the same genotype can remain dominant for more than one season (Venter et al., 2001). Even looking at the nucleotide level, HRSV isolates with identical G gene sequences could be seen over a 3-year period in one human community in the United States (Peret et al., 1998), or even for longer periods of 6-7 seasons in Germany (Reiche and Schweiger, 2009). This suggests that successful variants may be able to persist and remain dominant for more than one season. In our study, we also found HRSV isolates with identical G gene sequences in two distinct epidemics. This suggests that HRSV had already been introduced in 2005 and that multiple 
transmission events occurred. Another possibility is that the virus circulated within the different chimpanzee communities of the area and was propagated by chimpanzeeto-chimpanzee contact after the initial introduction of the virus into the population in 2005. However, contacts between neighboring groups are rare (Boesch and Boesch-Achermann, 2000; Boesch et al., 2008), and when chimpanzees are sick, they will not travel far or seek conflicts with neighbors. Within habituated chimpanzee groups, signs of respiratory disease have rarely been observed between outbreaks and, if so, only in one or few individuals.

It might also be possible that chimpanzees may not have been reinfected, but rather had very prolonged viral persistence/shedding, as persistent HRSV or HMPV infections without the presence of symptoms have been documented for immunocompromised humans (Debiaggi et al., 2006; Sikkel et al., 2008). Therefore, we tested fecal samples collected between the two HRSV and HMPV outbreaks, but all were negative, making it unlikely that the virus had persisted in the chimpanzees. But, all in all, we cannot exclude the possibility of persistence as the viral load may be too low to be detected in feces.

In humans, reinfections of HRSV with both the homologous and heterologous group are common and occur throughout life (Mufson et al., 1987; Hall et al., 1990; Sullender et al., 1998). In older children and adults, they are usually associated with milder disease, indicating that HRSV infections induce only incomplete immunity (Henderson et al., 1979). It has been assumed, that this is due to the variability between HRSV strains (Hall et al., 1990; Peret et al., 2000). In our study, individual chimpanzees became reinfected with the same subtype (based on the sequence data from three individuals). Reinfection with the same virus strain has also been observed in humans, for example, within 2 months in adults (Hall et al., 1991) and within 7-9 months in infants (Scott et al., 2006). These data raise questions about the strength of homologous protection.

Comparing the total number of HRSV-positive individuals in 2005 and 2006, there is a significant decrease in 2006, although observed morbidity was equally high in both outbreaks (Fig. 1). This is similar for the two consecutive HMPV outbreaks. This shows that the second epidemics were milder and resulted in lower and thus undetectable virus shedding, suggesting that chimpanzees had acquired some level of immunity, although not strong enough to prevent the reinfection. This is in contrast with a study where captive-bred chimpanzees were analyzed for seroprevalence and susceptibility to HMPV, which showed that previous infection by HMPV completely protects chimpanzees from reinfection, both for the homologous and for the heterologous group (Skiadopoulos et al., 2004).

The HMPV outbreak in 2004 had the highest mortality; in this outbreak, eight infants and juveniles died. As mentioned above, the second epidemics, both for HMPV and HRSV, showed a rather mild course of disease, probably due to acquired immunity. But the question arises: Why was mortality in the first HRSV epidemic (2005) so low? Especially considering that the first HMPV outbreak showed such a high degree of mortality. Previous studies with captive-bred chimpanzees showed that the pathogenicity of HRSV and HMPV is similar, if not even stronger for HRSV (Belshe et al., 1977; Skiadopoulos et al., 2004). Indeed, we already observed a severe HRSV outbreak in another community (North group) of Taï chimpanzees in 1999, which killed many chimpanzees (Köndgen et al., 2008). In humans, clinically severe HRSV infections occur predominantly in the course of the first infection, thus perhaps the chimpanzees of the South group were exposed to HRSV in earlier times. However, no hints for such outbreaks have been obtained through analyses of longterm observational data of the chimpanzees (Boesch and Boesch-Achermann, 2000). Unfortunately, no fecal samples were collected before 2001, thus molecular identification of earlier infections is not possible. However, there could be many reasons for the different mortality rates between epidemics. In humans, particularly among very young children, both HRSV and HMPV infections are associated with significant morbidity and mortality. Thus, another possibility for the higher mortality in 2004 might be a higher abundance of susceptible infants. However, the number of infants and juveniles in 2005 and 2006 was similar to that in 2004 (22 in 2004 vs. 16 in 2005 vs. 15 in 2006), but the mortality rate was much lower in 2005 and 2006 (see Table 1), suggesting that the abundance of infants and juveniles had no strong effect on mortality. Although environmental factors might have played a role, in a recent study, infant mortality rates of Taï chimpanzees were correlated to the average monthly values of either rainfall or an index of the availability of fruit, and no significant relationship was found (Kuehl et al., 2008). In addition, differences in the severity of the secondary bacterial infection might have caused the higher mortality in 2004. During this outbreak, not only Streptococcus pneumoniae but also Pasteurella multocida was found in the lung tissue of the chimpanzees (Chi et al., 2007) and might have influenced the lethal course of pneumonia. It is likely that it is not the viral infection which triggers 
severity of the outbreaks, but the key factors are bacterial secondary infections. What triggers such secondary infections requires further investigation, but factors such as stress and chronic infections may play a role.

Although protective measures like mask wearing had been implemented after the severe outbreak in 2004, chimpanzees became infected by HRSV and HMPV. Since 2006, compliance of mask wearing has improved and additional hygiene rules like hand washing before entering the forest have been implemented in the project (Boesch, 2008). These measures are known to be effective in public health and animal husbandry. Given the high infection pressure through growing human populations around protected areas with high disease burdens, the implementation of such measures is ethically "required." However, further data and long-term observations are needed to evaluate reduction of transmission by hygiene measures implemented. In addition, the effect of possible acquired immunity against specific pathogens should be considered and analyzed.

\section{Conclusions}

This study adds data to the growing body of evidence that endangered species are threatened and influenced by human diseases more than traditionally thought. To understand the influence of these human pathogens on wild primates, further studies comparing various sites and species are needed. New noninvasive methods, such as those described here, allow such studies and may not only serve to better understand diseases in wild great apes, but possibly also other threatened primate and nonprimate species.

\section{Acknowledgements}

We thank the Ivorian authorities for long-term support, especially the Ministry of the Environment and Forests as well as the Ministry of Research, the directorship of the Taï National Park, and the Swiss Research Centre in Abidjan. For support during field observations and sample collection we would like to thank the assistants of the Taï chimpanzee project. We are also grateful to B. Schweiger, B. Biere and J. Reichel for providing diagnostic assays and J. Tesch for technical support. We thank R. Mundry for statistical advice. For helpful discussion and copyediting, we gratefully acknowledge T. Gillespie, S.A. Leendertz and A. Goffe. This work was supported by the Robert Koch-Institut and the MaxPlanck-Society. 


\section{References}

Belshe RB, Richardson LS, London WT, Sly DL, Lorfeld JH, Camargo E, et al. (1977) Experimental respiratory syncytial virus infection of four species of primates. Journal of Medical Virology 1:157-162 Boesch C (2008) Why do chimpanzees die in the forest? The challenges of understanding and controlling for wild apes health American Journal of Primatology 70:722-726

Boesch C, Boesch-Achermann H (2000) The Chimpanzees of the Taï Forest: Behavioural Ecology and Evolution, Oxford/New York: Oxford University Press Boesch C, Kohou G, Néné H, Vigilant I (2006) Male competition and paternity in wild chimpanzees of the Taï Forest. American Journal of Physical Anthropology 130:103-115

Boesch C, Crockford C, Herbinger I, Wittig R, Moebius Y, Normand E (2008) Intergroup conflicts among chimpanzees in Taï National Park: lethal violence and the female perspective. American Journal of Primatology 70:519-532

Boivin G, De Serres G, Cote S, Gilca R, Abed Y, Rochette L, et al. (2003) Human metapneumovirus infections in hospitalized children. Emerging Infectious Diseases 9:634-640

Cane PA (2001) Molecular epidemiology of respiratory syncytial virus. Reviews in Medical Virology 11:103-116

Chi F, Leider M, Leendertz F, Bergmann C, Boesch C, Schenk S, et al. (2007) New Streptococcus pneumoniae clones in deceased wild chimpanzees. Journal of Bacteriology 189:6085-6088

Clarke CJ, Watt NJ, Meredith A, McIntyre N, Burns SM (1994) Respiratory syncytial virus-associated bronchopneumonia in a young chimpanzee. Journal of Comparative Pathology 110:207-212

Debiaggi M, Canducci F, Sampaolo M, Marinozzi MC, Parea M, Terulla C, et al. (2006) Persistent symptomless human metapneumovirus infection in hematopoietic stem cell transplant recipients. Journal of Infectious Diseases 194:474-478

Gillespie TR, Nunn CL, Leendertz FH (2008) Integrative approaches to the study of primate infectious disease: implications for biodiversity conservation and global health. American Journal of Physical Anthropology 137:53-69

Goodall J (1986) The Chimpanzees of Gombe: Patterns of Behaviour, Cambridge, MA: Harvard University Press Hall CB, Walsh EE, Long CE, Schnabel KC (1991) Immunity to and frequency of reinfection with respiratory syncytial virus. Journal of Infectious Diseases 163:693-698

Hall CB, Walsh EE, Schnabel KC, Long CE, McConnochie KM, Hildreth SW, et al. (1990) Occurrence of groups $A$ and $B$ of respiratory syncytial virus over 15 years: associated epidemiologic and clinical characteristics in hospitalized and ambulatory children. Journal of Infectious Diseases 162:1283-1290 Hall TA (1999) BioEdit: a user-friendly biological sequence alignment editor and analysis program for Window 95/98/NT. Nucleic Acids Symposium Series 41:95-98

Hanamura S, Kiyono M, Lukasik-Braum M, Mlengeya T, Fujimoto M, Nakamura M, et al. (2008) Chimpanzee deaths at Mahale caused by a flu-like disease. Primates 49:77-80

Henderson FW, Clyde WA Jr, Collier AM, Denny FW, Senior RJ, Sheaffer Cl, et al. (1979) The etiologic and epidemiologic spectrum of bronchiolitis in pediatric practice. Journal of Pediatrics 95:183-190

Herbinger I, Boesch C, Rothe $H$ (2001) Territory characteristics among three neighboring chimpanzee communities in the Taï National Park, Côte d'Ivoire. International Journal of Primatology 22:143-167

Hess M, Huggins MB, Mudzamiri R, Heincz U (2004) Avian metapneumovirus excretion in vaccinated and non-vaccinated specified pathogen free laying chickens. Avian Pathology 33:35- 40

Homsy J (1999) Ape tourism and human diseases: how close should we get? Available: http://www.igcp.org/pdf/homsy_rev.pdf

Kaur T, Singh J, Tong S, Humphrey C, Clevenger D, Tan W, et al. (2008)Descriptive epidemiology of fatal respiratory outbreaks and detection of a human-related metapneumovirus in wild chimpanzees (Pan troglodytes) at Mahale Mountains National Park, Western Tanzania. American Journal of Primatology 70:755-765

Keele BF, Van Heuverswyn F, Li Y, Bailes E, Takehisa J, Santiago ML, et al. (2006) Chimpanzee reservoirs of pandemic and nonpandemic HIV-1. Science 313:523-526

Köndgen S, Kühl H, N'Goran PK, Walsh PD, Schenk S, Ernst N, et al. (2008) Pandemic human viruses cause decline of endangered great apes. Current Biology 18:260-264

Kuehl HS, Elzner C, Moebius Y, Boesch C, Walsh PD (2008) The price of play: self-organized infant mortality cycles in chimpanzees. PLoS One 3:e2440

Leendertz FH, Pauli G, Maetz-Rensing K, Boardman W, Nunn C, Ellerbrok H, et al. (2006) Pathogens as drivers of population declines: the importance of systematic monitoring in great apes and other threatened mammals. Biological Conservation 131:325-337 
Liu W, Worobey M, Li Y, Keele BF, Bibollet-Ruche F, Guo Y, et al. (2008) Molecular ecology and natural history of simian foamy virus infection in wild-living chimpanzees. PLoS Pathogens 4:e1000097

Mackay IM, Bialasiewicz S, Waliuzzaman Z, Chidlow GR, Fegredo DC, Laingam S, et al. (2004) Use of the $\mathrm{P}$ gene to genotype human metapneumovirus identifies 4 viral subtypes. The Journal of Infectious Diseases 190:1913-1918

Makuwa M, Souquie're S, Clifford SL, Mouinga-Ondeme A, Bawe- Johnson M, Wickings EJ, et al. (2005) Identification of hepatitis B virus genome in faecal sample from wild living chimpanzee (Pan troglodytes troglodytes) in Gabon. Journal of Clinical Virology 34:S83-S88

Mufson MA, Belshe RB, Orvell C, Norrby E (1987) Subgroup characteristics of respiratory syncytial virus strains recovered from children with two consecutive infections. Journal of Clinical Microbiology 25:1535-1539

Mundry R, Fischer J (1998) Use of statistical programs for nonparametric tests of small samples often leads to incorrect Pvalues: examples from animal behaviour. Animal Behaviour 56:256-259

Nishida T, Corp N, Hamai M, Hasegawa T, Hiraiwa-Hasegawa M, Hosaka K, et al. (2003) Demography, female life history, and reproductive profiles among the chimpanzees of Mahale. American Journal of Primatology 59:99-121

Peret TC, Hall CB, Hammond GW, Piedra PA, Storch GA, Sullender WM, et al. (2000) Circulation patterns of group $A$ and $B$ human respiratory syncytial virus genotypes in 5 communities in North America. Journal of Infectious Diseases 181:1891-1896

Peret TC, Hall CB, Schnabel KC, Golub JA, Anderson LJ (1998) Circulation patterns of genetically distinct group $A$ and $B$ strains of human respiratory syncytial virus in a community. Journal of General Virology 79(Pt 9):2221-2229

Reiche J, Schweiger B (2009) Genetic variability of group A human respiratory syncytial virus strains circulating in Germany from 1998 to 2007. Journal of Clinical Microbiology 47:1800-1810

Santiago ML, Rodenburg CM, Kamenya S, Bibollet-Ruche F, Gao F, Bailes E, et al. (2002) SIVcpz in wild chimpanzees. Science 295:465

Sato M, Saito R, Sakai T, Sano Y, Nishikawa M, Sasaki A, et al. (2005) Molecular epidemiology of respiratory syncytial virus infections among children with acute respiratory symptoms in a community over three seasons. Journal of Clinical Microbiology 43:36-40

Scott PD, Ochola R, Ngama M, Okiro EA, James Nokes D, Medley GF, et al. (2006) Molecular analysis of respiratory syncytial virus reinfections in infants from coastal Kenya. Journal of Infectious Diseases 193:59-67

Siegel S, Castellan NJ (1988) Nonparametric Statistics for the Behavioral Sciences, New York: McGraw-Hill Sikkel MB, Quint JK, Mallia P, Wedzicha JA, Johnston SL (2008) Respiratory syncytial virus persistence in chronic obstructive pulmonary disease. Pediatric Infectious Disease Journal 27:S63- S70

Skiadopoulos MH, Biacchesi S, Buchholz UJ, Riggs JM, Surman SR, Amaro-Carambot E, et al. (2004) The two major human metapneumovirus genetic lineages are highly related antigenically, and the fusion $(F)$ protein is a major contributor to this antigenic relatedness. Journal of Virology 78:6927-6937 Sullender WM, Mufson MA, Prince GA, Anderson LJ, Wertz GW (1998) Antigenic and genetic diversity among the attachment proteins of group A respiratory syncytial viruses that have caused repeat infections in children. Journal of Infectious Diseases 178:925-932

Szentiks CA, Köndgen S, Silinski S, Speck S, Leendertz FH (2009) Lethal pneumonia in a captive juvenile chimpanzee (Pan troglodytes) due to human-transmitted human respiratory syncytial virus (HRSV) and infection with Streptococcus pneumoniae. Journal of Medical Primatology 38:236-240 Venter M, Madhi SA, Tiemessen CT, Schoub BD (2001) Genetic diversity and molecular epidemiology of respiratory syncytial virus over four consecutive seasons in South Africa: identification of new subgroup $A$ and $B$ genotypes. Journal of General Virology 82:2117-2124

von Linstow ML, Eugen-Olsen J, Koch A, Winther TN, Westh H, Hogh B (2006) Excretion patterns of human metapneumovirus and respiratory syncytial virus among young children. European Journal of Medical Research 11:329-335

Weber MW, Mulholland EK, Greenwood BM (1998) Respiratory syncytial virus infection in tropical and developing countries. Tropical Medicine \& International Health 3:268-280

Woodford MH, Butynski TM, Karesh WB (2002) Habituating the great apes: the disease risks. Oryx 36:153-160 


\section{Tables and Figures}

Table 1. Characteristics of Respiratory Epidemics Observed in the South Group of Taï Chimpanzees and Molecular Results of Fecal Samples Including Healthy Control Group

\begin{tabular}{|c|c|c|c|c|c|}
\hline & March 2004 & October 2004 & August 2005 & February 2006 & Control \\
\hline Observed symptoms & Respiratory & Respiratory & Respiratory & Respiratory & No symptoms \\
\hline Morbidity ${ }^{a}$ & $100 \%$ & $64 \%^{e}$ & $100 \%$ & $92 \%$ & 0 \\
\hline Total mortality ${ }^{\mathrm{b}}$ & $8 / 44$ & $0 / 35$ & $0 / 35$ & $1 / 34$ & 0 \\
\hline Adults/adolescents ${ }^{c}$ & $0 / 22$ & $0 / 20$ & $0 / 19$ & $0 / 19$ & 0 \\
\hline Juveniles/infants ${ }^{c}$ & $8 / 22$ & $0 / 12$ & $1 / 16$ & $1 / 15$ & 0 \\
\hline $\begin{array}{l}\text { Viruses identified from } \\
\text { tissue samples }\end{array}$ & HMPV & $\begin{array}{l}\text { No tissue samples } \\
\text { available }\end{array}$ & $\begin{array}{l}\text { No tissue samples } \\
\text { available }\end{array}$ & HRSV & $\begin{array}{l}\text { No tissue samples } \\
\text { available }\end{array}$ \\
\hline $\begin{array}{l}\text { Pathogens identified from } \\
\text { fecal samples }\end{array}$ & HMPV & HMPV & HRSV & HRSV & None \\
\hline Positive-tested fecal samples ${ }^{d}$ & $37 / 65$ & $3 / 29$ & $43 / 60$ & $7 / 42$ & $0 / 54^{\mathrm{f}}$ \\
\hline Positive-tested individuals & $21 / 29(72 \%)$ & $1 / 15(7 \%)$ & $22 / 24(92 \%)$ & $6 / 24(25 \%)$ & $0 / 21^{f}$ \\
\hline
\end{tabular}

HMPV, human metapneumovirus; HRSV, human respiratory syncytial virus.

${ }^{a}$ Morbidity refers to the total number of weaned individuals observed with respiratory symptoms during an epidemic.

${ }^{\mathrm{b}}$ Mortality refers the number of cases of deaths due to respiratory disease, excluding indirect cases.

${ }^{\mathrm{c}}$ Age classes for Taï chimpanzees: infant, $0-5$ years; juvenile, 5-10 years; adolescent, 10-15 years; adult, $>15$ years.

${ }^{\mathrm{d}}$ Based on all available fecal samples which had been collected during the respiratory disease outbreaks. Individuals were sampled 1-7 times except for the control group.

${ }^{\mathrm{e}}$ The number of symptomatic individuals in October 2004 could only be estimated because observational data was not recorded continuously during this outbreak.

${ }^{\mathrm{f}}$ Control samples were selected from a period when the whole group appeared healthy and showed no respiratory symptoms: In June/July 2005, one sampled from each of 21 individuals was tested for the presence of HMPV and HRSV. To determine if these viruses were persistent in affected individuals, additional samples which had been collected in the time between consecutive outbreaks of HMPV or HRSV were tested: Thirteen samples from five individuals which had been observed with symptoms in both the HMPV outbreak in March and October 2004 were tested for HMPV. Similarly, 20 samples from six individuals that tested HRSV-positive in both the RSV outbreak in August 2005 and February 2006 were tested for HRSV. 
Figure 1. Shown is the percentage of infected individuals in (A) the HMPV outbreaks in 2004 and (B) the HRSV outbreaks in 2005 and 2006. Observed morbidity (striped) was high in all outbreaks, while the percentages of positive-tested individuals (dark gray) decreased in the consecutive outbreaks, both for HMPV and HRSV. The number of symptomatic individuals in October 2004 could only be estimated because observational data was not recorded continuously during this outbreak (e). HMPV, human metapneumovirus; HRSV, human respiratory syncytial virus.

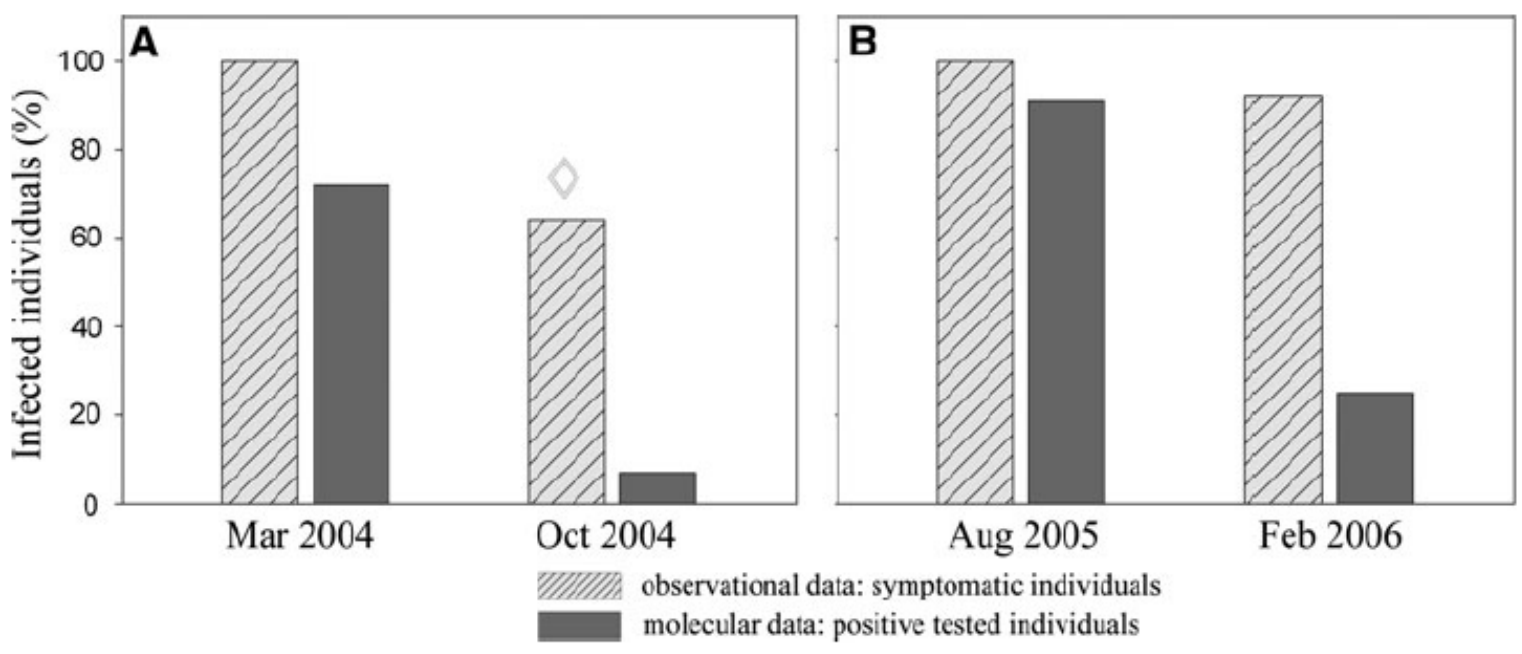


Figure 2. Shown are the time trends of the HMPV outbreak in March 2004 and the HRSV outbreak in 2005 and 2006. Data is based on the percentage of individuals seen with signs of respiratory symptoms (shaded gray) and samples tested positive for HMPV or HRSV by molecular analysis of fecal samples (shaded colored). Data from every 2 days were pooled to avoid sample size $<2$. The viral load is color-coded differentiating between low (yellow), medium (orange), and high (red) copy numbers (according to the range of viral copy numbers, logarithmised to the base of 10 , separately for HMPV and HRSV). Number symbols (\#) indicate that no fecal samples had been collected during these days. HMPV, human metapneumovirus; HRSV, human respiratory syncytial virus.
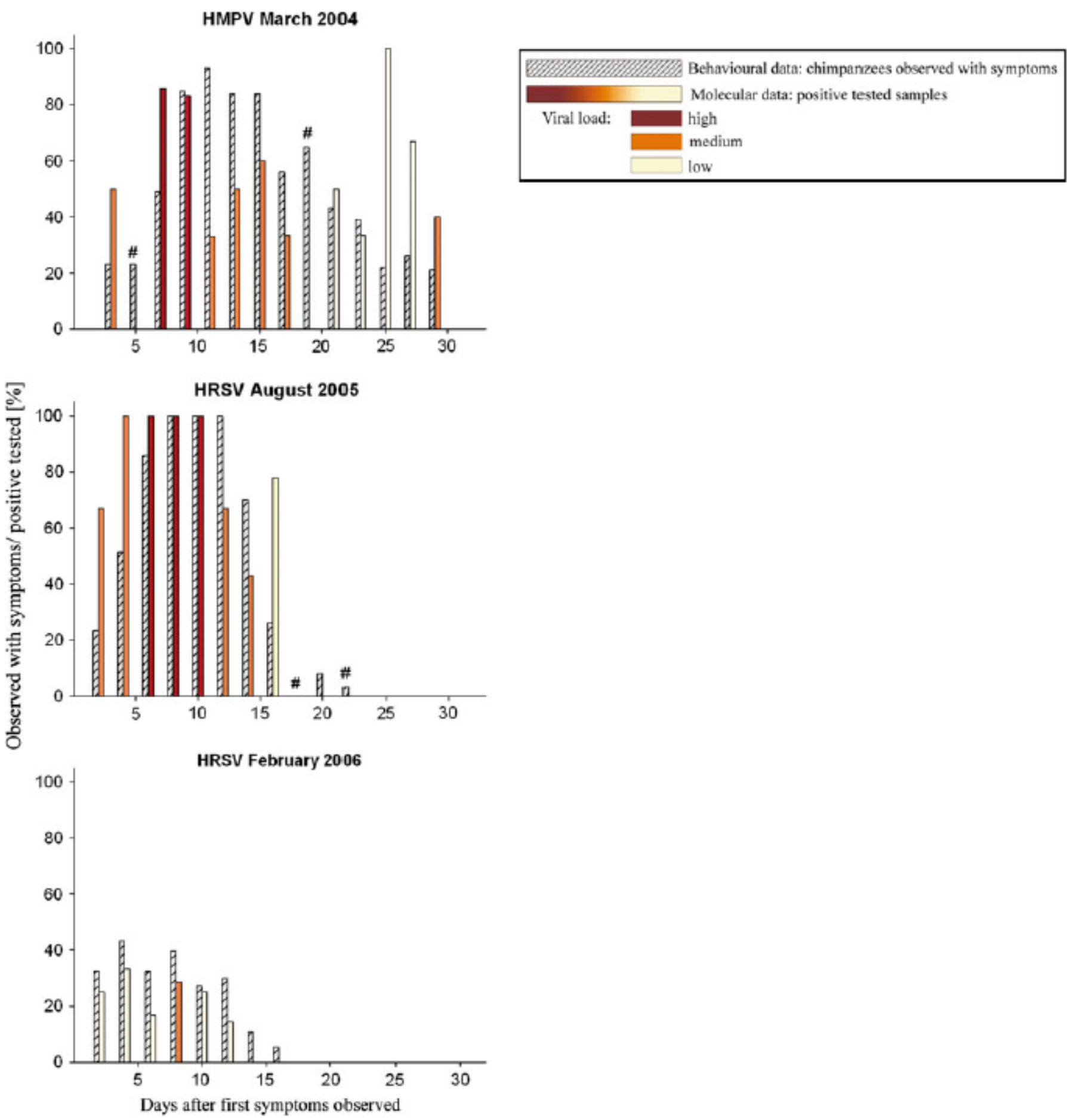